\title{
VASCULAR COMPLICATION IN AESTHETIC MEDICINE TREATED WITH HYPERBARIC OXYGENATION
} \author{
Dorota Niewiedział ${ }^{4}$, Piotr Siermontowski ${ }^{1}$, Ewa Zieliński ${ }^{5}$ ) \\ Wojciech \\ 1) Department of Maritime and Hyperbaric Medicine, Military Medical Institute of Gdynia, Poland \\ ${ }^{2)}$ Academy of Face Sculpting, Poland \\ ${ }^{3}$ Department of Microbiology, Medical University of Warsaw, Poland \\ ${ }^{4}$ Department of Human Development Psychology, University of Zielona Góra, Poland \\ Department of Emergency Medicine and Disaster Medicine, Poland
}

Marusza ${ }^{2}$,

Irina Netsvyetayeva ${ }^{3)}$,

\section{ABSTRACT}

The most hazardous adverse reactions following hyaluronic acid injections in aesthetic medicine involve vascular complications, known as the Nicolau Syndrome. This article presents a vascular complication in the area of the upper part of the nasolabial fold following subcutaneous administration of $0.5 \mathrm{ml}$ of hyaluronic acid. At the time of the injection, paling occurred, which was followed by livedo racemosa appearing an hour later. Upon the lapse of a week, an ulceration appeared. It was not until the tenth day after the hyaluronic acid injection that hyaluronidase was administered. After 15 hyperbaric oxygen exposures, the ulcer was completely healed.

Keywords: hyaluronic acid, Nicolau Syndrome, cardiovascular complication, hyperbaric oxygenation.

ARTICLE INFO

PolHypRes 2018 Vol. 63 Issue 2 pp. 33 - 38

ISSN: 1734-7009 elSSN: 2084-0535

Casuistic (case description) article

DOI: $10.2478 / p h r-2018-0010$

Pages: 6 , figures: 3 , tables: 0

Submission date: $20.04 .2018 \mathrm{r}$.

page www of the periodical: www.phr.net.pl

Acceptance for print: $15.05 .2018 \mathrm{r}$

Publisher

Polish Hyperbaric Medicine and Technology Society 


\section{INTRODUCTION}

Currently, aesthetic medicine uses 160 fillers produced by 50 producers to correct wrinkles and furrows. The most popular filler is hyaluronic acid, which was first used in September 1996. It was a cross-linked derivative of hyaluronic acid obtained from Streptococcus bacteria [1].

Adverse reactions following the use of hyaluronic acid constitute an important problem in aesthetic medicine. A misdiagnosis may involve a longlasting ineffective therapy, whereas proper diagnosis results in a quick healing process. Adverse reactions after the injection of hyaluronic acid may be divided into early and delayed reactions.

Early adverse reactions (erythema, oedema, callosity) usually disappear within a few days following an injection of hyaluronic acid and depend mainly on the level of proteins and bacterial endotoxins [2].

Delayed reactions occur in about $1 \%$ of cases in the form of papules, granulomas, ulcers and biofilms. They may occur several days, weeks or months, or even years following administration of hyaluronic acid [4].
However, the most dangerous adverse reactions following the injections with hyaluronic acid are vascular complications, i.e. the Nicolau Syndrome, which typically occurs during the injection or a few hours after its administration $[3,4]$

Below we present a case of an occurrence of vascular complications following the administration of hyaluronic acid.

\section{CASE DesCription}

A beautician administered to a 45-year-old woman a subcutaneous dose of $0.5 \mathrm{ml}$ of hyaluronic acid under the upper part of the nasolabial fold. Immediately after the administration of the filler, paling and pain occurred at the injection site. One hour after the injection, retinoblastoma (livedo racemosa) occurred as well as pain radiating to the left eye and a watery secretion from the left nasal passage and tearing of the left eye. Also, a sore which had developed in the locality of the application of the hyaluronic acid intensified (fig. 1). The next day, the beautician diagnosed herpes and recommended local treatment (fig. 2).

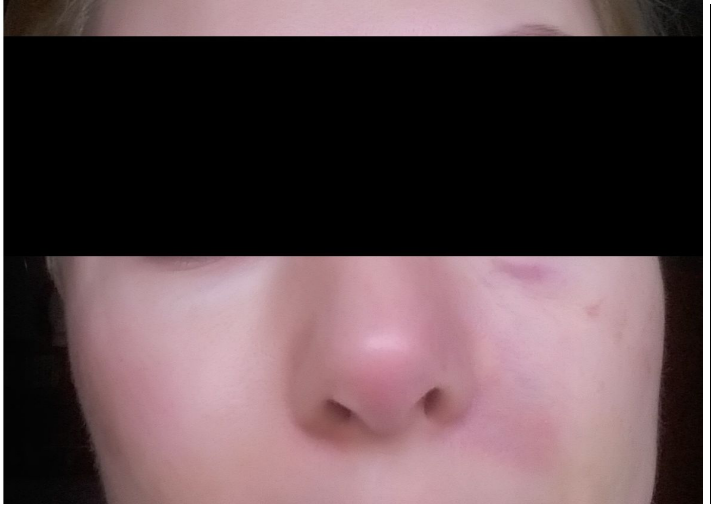

Fig. 1

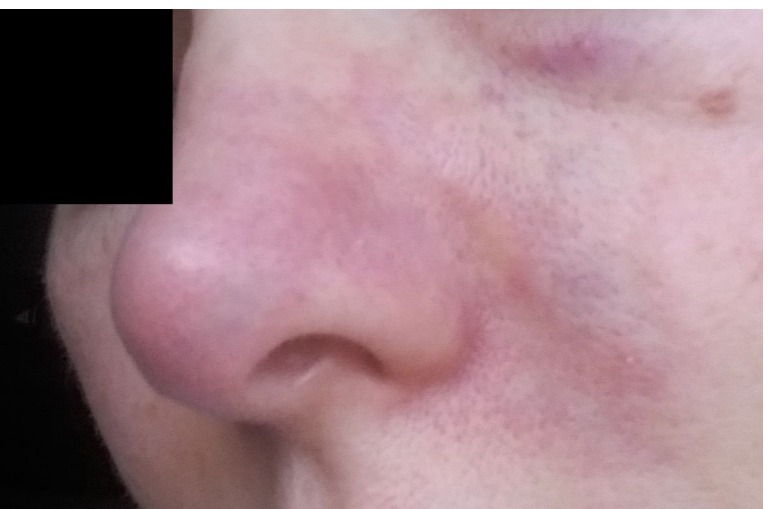

Fig. 2

Three days later, the woman appeared for consultation at the Emergency Ward in a hospital. An antibiotic ointment was prescribed (fig. 3). Oedema and pain in the locality in which the filler was administered had increased, and an ulcer appeared within a week of the treatment (fig. 4).

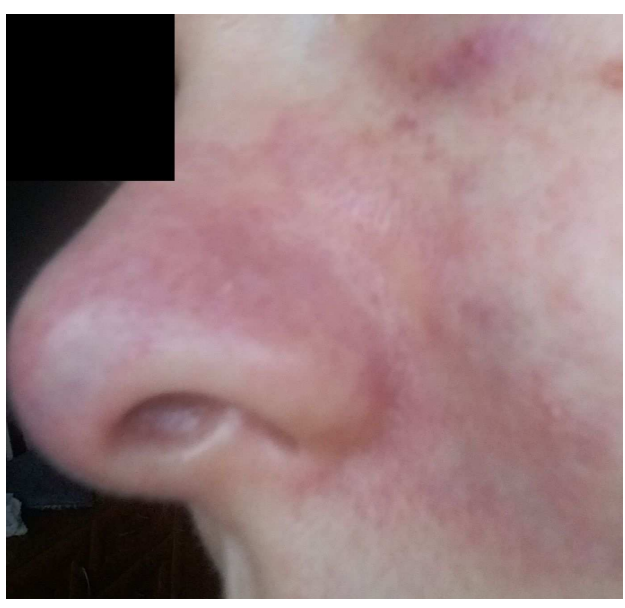

Fig. 3

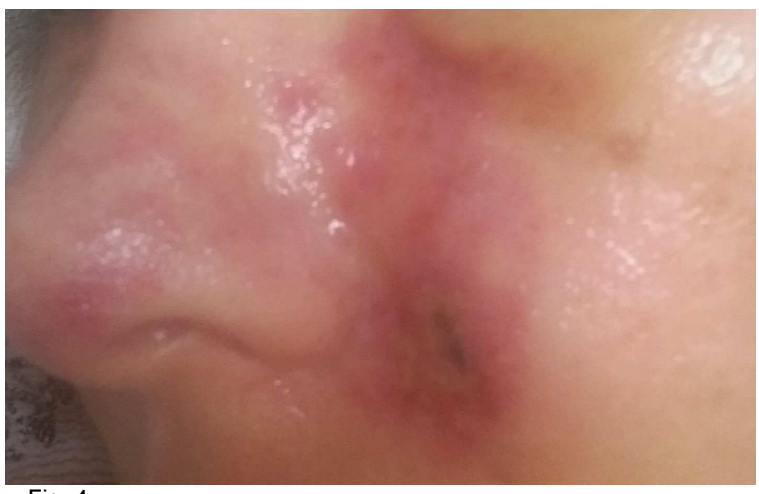

Fig. 4 
It was not until the tenth day following the injection of hyaluronic acid in the upper part of the nasolabial fold that $100 \mathrm{U}$ of hyaluronidase was administered to the patient for the purpose of dissolving the filler. In addition, an antibiotic therapy (ciprofloxacin and clarithromycin) and prednisone (fig. 5) were used.

As a result of this, by the next day, the pain subsided and the swelling decreased. To accelerate the treatment of the ulcer, the use of hyperbaric oxygen
(HBO) was recommended. Each HBO session at 2.5 ATA pressure lasted 90 minutes during which the patient breathed oxygen with 5-minute breaks during which she breathed air. During HBO treatment, the ulcer was gradually reduced and after 15 exposures the ulcer was completely healed. At present, there is mild scarring at the place of ulceration (fig. 6, 7).

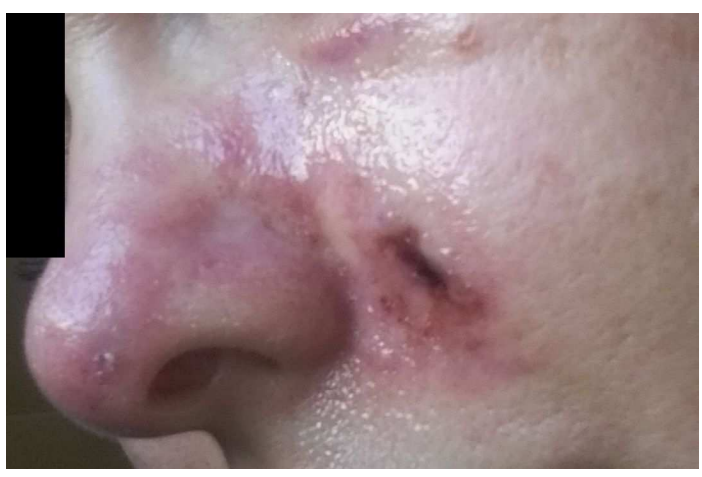

Fig. 5

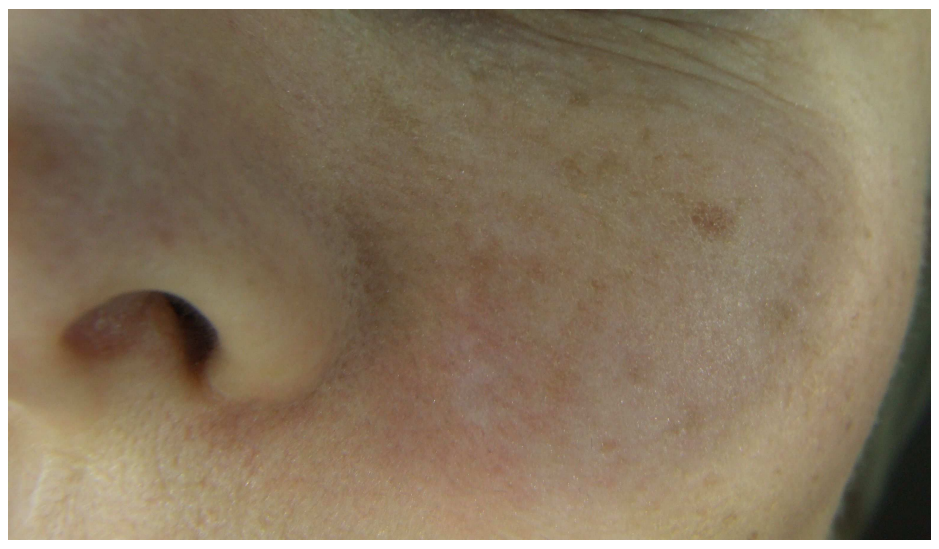

Fig. 7

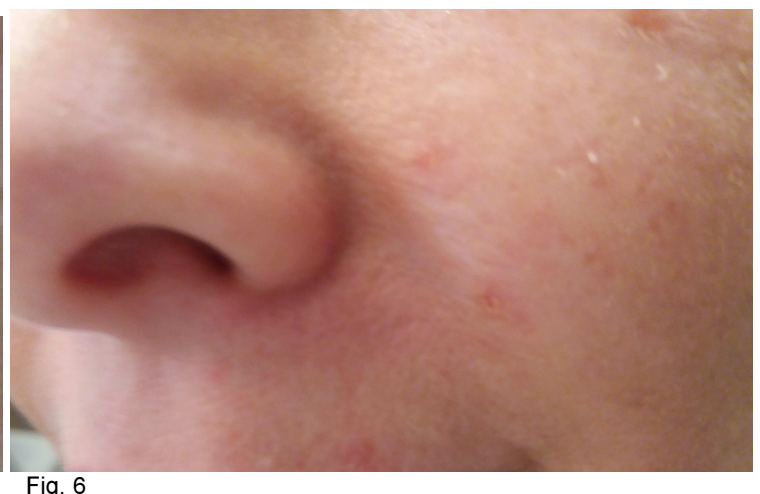

Fig. 6

\section{DisCUSSION}

In recent years, aesthetic medicine procedures are frequently performed by unqualified persons, e.g. beauticians. The patient was not informed by the beautician about the possibility of an occurrence of adverse reactions. Already during the administration of the filler, skin paling and pain appeared at the injection site. The beautician disregarded the symptom as she was not familiar with the possible adverse reactions following an injection of hyaluronic acid. Upon the lapse of just a few hours, livedo racemosa occurred around the apex of the nose and the upper left side of the nasolabial furrow. The beautician diagnosed herpes and recommended local treatment. On the third day the patient arrived at the emergency ward at a hospital where only a bacterial infection was diagnosed and an antibiotic ointment prescribed. On the seventh day following the injection, an ulcer occurred around the upper left nasolabial furrow. It was not until the tenth day after the application of the hyaluronic acid that the right treatment was applied. Following an intradermal test, $100 \mathrm{U}$ of hyaluronidase was administered to the upper nasolabial furrow region. Already a few minutes after the injection of hyaluronidase, the pain subsided and the swelling decreased. In order to accelerate the treatment of ulcers, the use of hyperbaric oxygenation was recommended.

Before administering hyaluronidase an allergic test should be performed - in rare cases, urticaria or angioedema may occur (in $0.1 \%$ of patients) following the administration of hyaluronidase. Hyaluronidase is of an animal origin (bovine or ovine) and the occurring allergy may be of type I (immediate) and IV (delayed).

In the described case, only a compression of the facial artery by hyaluronic acid occurred. The symptoms included paling and pain at the injection site. In such an event it is required to interrupt the procedure and immediately administer hyaluronidase for the purpose of dissolving the hyaluronic acid $[1,2,3,4,5]$. If ulceration occurs, it is necessary to apply hyperbaric oxygenation [6].

Intravascular injections are much more serious as the administration of as little as $0.05 \mathrm{ml}$ of hyaluronic acid may result in blindness $[1,2,3,4,5]$. Anatomic changes in the facial vessels make the procedure unpredictable. Injections with hyaluronic acid in the nasal region are particularly hazardous. The dorsal nasal artery, which constitutes the terminal branch of the ophthalmic artery, 
may be single or double. The size of a single nasal dorsal artery may reach as much as $1 \mathrm{~mm}$ [4].

Another hazardous area is the nasolabial fold through which the facial artery passes and then transfers into the angular artery that connects with the ophthalmic artery [3]. In the described case, vascular symptoms occurred as a result of compression on the facial artery with hyaluronic acid.

\section{ConCLUSiOnS}

- The augmentation of wrinkles and furrows should only be performed by physicians who know the anatomy and rules of conduct in the case of an occurrence of adverse reactions.

- Vascular complications are among the most serious complications in aesthetic medicine.

- In the event of an occurrence of skin paling and pain while administering hyaluronic acid, it is required to immediately stop the treatment and administer hyaluronidase to dissolve the filler.

- Hyperbaric oxygenation may play an important role in the treatment of vascular complications of aesthetic medicine.

\section{REFERENCES}

1. Wang M, Li W, Zhang Y, Tian W, Wang H. Comparison of Intra-arterial and Subcutaneous Testicular Hyaluronidase Injection Treatments and the Vascular Complications of Hyaluronic Acid Filler. Dermatol Surg 2017;43:246-254;

2. Pierre Andre \& Eckart Haneke Nicolau syndrome due to hyaluronic acid injections, Journal of Cosmetic and Laser Therapy 1-5 2016;

3. Kim J, Hwang W. Forehead reconstruction using modified doubleopposing rotation-advancement flaps for severe skin necrosis after filler injection. Arch Craniofac Surg 19, 1, 64-67, 2018;

4. Tansatit T . et al. Facing the Worst Risk: Confronting the Dorsal Nasal Artery, Implication for Non-surgical Procedures of Nasal Augmentation. Aesth Plast Surg 41:191-198, 2017;

5. Myung $Y$ et al. The Classification and Prognosis of Periocular Complications Related to Blindness following Cosmetic Filler Injection. Plast. Reconstr. Surg. 140: 61, 2017;

6. Henderson R, Reilly DA, Cooper JS. Hyperbaric Oxygen for Ischemia due to Injection of Cosmetic Fillers: Case Report and Issues. Plast Reconstr Surg Glob Open 6:e1618; 2018;

7. Andre P, Fléchet ML. Angioedema after ovine hyaluronidase injection for treating hyaluronic acid overcorrection Journal of Cosmetic Dermatology $7,136-138,2008$

prof. dr hab. med. Romuald Olszański

Zakład Medycyny Morskiej I Hiperbarycznej

Wojskowy Instytut Medyczny

ul. kmdr. Grudzińskiego 4

81-103 Gdynia 3

romuald.olszanski@wp.pl 